\title{
Role of spiramycin/cotrimoxazole association in the mother-to-child transmission of toxoplasmosis infection in pregnancy
}

\author{
P. Valentini • M. L. Annunziata $\cdot$ D. F. Angelone $\cdot$ \\ L. Masini • M. De Santis • A. Testa • R. L. Grillo • \\ D. Speziale • O. Ranno
}

Published online: 20 May 2009

(C) Springer-Verlag 2009

\section{Erratum to: Eur J Clin Microbiol Infect Dis DOI 10.1007/s10096-008-0612-5}

In the published original version of this article, page 298, $23 \mathrm{rd}$ line, the data in brackets $\left(3 \times 10^{6}\right.$ International Unit $=$ $\mathbf{3 . 4 8 0} \mathrm{g}$ ) is not given correct.

The line should read:

spiramycin, $3 \times 10^{6} \mathrm{IU}\left(3 \times 10^{6}\right.$ International Unit $\left.=870 \mathrm{mg}\right)$

The online version of the original article can be found at http://dx.doi. org/10.1007/s10096-008-0612-5

P. Valentini $(\bowtie) \cdot$ M. L. Annunziata $\cdot$ D. F. Angelone $\cdot$ A. Testa $\cdot$

O. Ranno

Department of Pediatrics, Pediatric Infectious Diseases Unit,

Catholic University of the Sacred Heart,

L.go A. Gemelli, 8,

00168 Rome, Italy

e-mail: pvalentini@rm.unicatt.it

L. Masini $\cdot$ M. De Santis

Department of Obstetrics and Gynecology,

Catholic University of the Sacred Heart,

Rome, Italy

R. L. Grillo $\cdot$ D. Speziale

Institute of Microbiology, Catholic University of the Sacred Heart,

Rome, Italy 